\title{
AIDS-Related Lymphomas in Nigeria
}

\author{
R.A. Bolarinwa, M.A. Ndakotsu, A.A. Oyekunle, L. Salawu, N.O. Akinola and M.A. Durosinmi \\ Department of Haematology and Immunology Obafemi Awolowo University and Obafemi Awolowo University Teaching Hospitals Complex, \\ Ile-Ife, Nigeria
}

\begin{abstract}
Aggressive non-Hodgkin's lymphoma (NHL), including primary central nervous system (CNS) lymphoma, lymphoblastic lymphoma and non-endemic Burkitt's lymphoma have been recognized as AIDS-defining cancers in most developed countries. However, HIV/AIDS epidemics appear not to have been associated with higher incidence of lymphomas in Africa. We therefore carried out this study to highlight the significance or otherwise of HIV/AIDS epidemics in the pathogenesis of lymphomas in a population of Nigerians with the disease. Since January 1993 to the present, all patients with haematologic cancers are routinely screened (following appropriate counseling) for HIV infection. Patients with a histological diagnosis of malignant chronic lymphoproliferative diseases \{non-Hodgkin lymphoma (NHL), chronic lymphocytic leukaemia (CLL), Burkitt's lymphoma (BL) and Hodgkin lymphoma (HL)\} at the Obafemi Awolowo University Teaching Hospitals' Complex, Ile-Ife from January 1993 to August 2008 were noted. Those patients confirmed to be HIV/AIDS positive among the cohort with lymphomas were retrospectively studied using their clinical case notes. Data obtained were analyzed using appropriate descriptive and inferential statistics. A total of $\mathbf{3 9 1}$ patients were histologically confirmed to have lymphoma \{NHL-109, (27.9\%); CLL-76, (19.4\%); BL-178, (45.5\%) and HL-28, (7.2\%)\} during the study period. Nine patients $(2.3 \%)$ were confirmed to be HIV- positive, all within the age bracket 24-60 (median = 50) years. Six of these, five males and one female, ages 24-60 (median $=37.5$ ) years, had NHL while another three, all females (age 50 - 68years; median = 56 years) had CLL. None of the patients with HL and BL were HIV positive. Patients with NHL presented at advanced stage of the disease (at least clinical stage IIIb), and all those with CLL presented at stage $C$ of the International Working Party Classification. All the HIV-positive patients with NHL succumbed to the disease within one to three weeks of admission into the hospital. The prevalence of AIDS-related lymphomas is $2.3 \%$ compared to $4.4 \%$ found in the general population. However, it is interesting that no single case of AIDS-associated BL was seen, despite the fact that Burkitt's lymphoma is endemic in this part of the world. All the patients presented at a very advanced stage of the disease with significantly shortened survival.
\end{abstract}

Key-Words: HIV/AIDS, lymphoma, Nigerians.

Lymphomas in human immunodeficiency virus (HIV) positive individuals are predominantly aggressive B cell diseases and are considered acquired immune deficiency syndrome (AIDS) defining and often time are the initial manifestation of AIDS [1]. The common HIV-associated lymphomas include Burkitt's lymphoma (BL); other less aggressive non-Hodgkin's Lymphomas (NHL) such as diffuse large B-cell lymphoma (DLBCL); primary effusion lymphoma (PEL), plasmablastic (lymphoblastic) lymphoma of the oral cavity and primary central nervous system lymphoma [2,3]. Since 1981 when the virus was first discovered in the United States, the incidence of lymphomas have been on the increase [4]. Before the advent of highly active antiretroviral therapy (HAART), primary central nervous system lymphoma and BL was reported to have increased 1000 fold, incidence of Hodgkin's lymphoma increased up to eight fold and NHL increased 60-200 fold [5-7]. Epidemiological studies also

Received on 3 May 2009; revised 15 September 2009.

Address for correspondence: Dr. RA Bolarinwa. Department of Haematology and Immunology, Faculty of Basic Medical Sciences, Obafemi Awolowo University, Ile-Ife, Nigeria. E-mail: bolarinwaraa@yahoo.co.uk, rbolarin@oauife.edu.ng. Phone: +234 803 7115854.

The Brazilian Journal of Infectious Diseases 2009;13(5):359-361. (C) 2009 by The Brazilian Journal of Infectious Diseases and Contexto Publishing. All rights reserved. confirmed the influence of HIV/AIDS on the geographic pattern of NHL and other cancers including those that were non AIDS-defining [7]. The risk for cancer was increased in both AIDS-defining and non AIDS-defining malignancies [8,9].

In most reports, NHL remains mostly affected by the HIV pandemic [7-10]; in all, AIDS-related lymphoma is an increasing cause of morbidity and mortality in regions of the world where the burden of HIV infection is greatest, such as Africa [11]. Lymphomas in HIV patients are heterogeneous with several pathogenetic mechanisms; including chronic antigen stimulation, genetic abnormalities, and cytokine dysregulation. Also, the impairment of the normal function of natural killer cells as a result of lack of helper signals from CD4+ T-lymphocytes is suggested to be a major mechanism of increased susceptibility to cancer development [12-14].

HIV-related lymphomas are monoclonal and are characterized by genetic abnormalities involving oncogenes MYC, BCL-6 and the tumour suppressor genes [2]. Erbstein Barr virus (EBV) is identified in neoplastic cells of approximately $60 \%$ of patients with HIV-related lymphomas [2]. The first reported case of HIV/AIDS in Nigeria was in 1986 [15] and following the pandemic the sero-prevalence of HIV/AIDS in Nigeria has risen from $1.8 \%$ in 1991 to $4.4 \%$ in 2005 [16]. This study therefore sought to highlight the significance or 
otherwise of HIV/AIDS pandemic in a population of Nigerians with lymphomas.

\section{Material and Methods}

Since January 1993, all patients with haematologic cancers are routinely screened (following appropriate counseling) for HIV 1 and 2 infections.

All patients with a histological diagnosis of malignant chronic lymphoproliferative diseases including NHL, CLL, $\mathrm{BL}$ and $\mathrm{HL}$ at the Obafemi Awolowo University Teaching Hospitals Complex (OAUTHC), Ile-Ife from January 1993 to August 2008 were reviewed. Information was obtained for patients that were confirmed HIV positive amongst this cohort. These include patients' biodata, histological type of the cancer and clinical staging at diagnosis, haematologic and biochemical results and therapy/treatment outcome. Data were analyzed using appropriate descriptive and inferential statistics and a p-value $\leq 0.05$ were statistically significant.

\section{Results}

A total of 391 patients were histologically confirmed with lymphomas: BL-178 (45.5\%); NHL-109 (27.9\%); CLL76 (19.4\%), and HL-28 (7.2\%) during the period under review. Of these, nine patients (2.3\%) were confirmed HIV positive. Their ages ranged from 24-60 (median=50) years. Table 1 shows the percentage of HIV-positive patients amongst different lymphoma sub-group. Many more patients were males (Male: Female ratio $=5: 4$ ).

Six patients, male $/$ female $=5 / 1$, aged 24-60 $($ median $=$ 37.5) years had NHL while three, all females aged 50-68 (median $=56$ ) years had CLL. None of the patients with HL and BL were HIV positive. All patients with NHL presented at a clinically advanced stage of the disease (at least clinical stage IIIb) and one patient (11.1\%) had co-infection with pulmonary tuberculosis. All patients with CLL presented in stage C (International Working Party classification). None of these patients lived long enough to have chemotherapy or antiretroviral agents. All the patients with NHL succumbed to their disease within one to three weeks of admission into our facility.

\section{Discussion}

The incidence of AIDS-related lymphoma in this study is $2.3 \%$. Earlier reports shows that the burden of HIV infection parallel the increasing morbidity and mortality from AIDS related lymphomas, most especially in regions of the world where prevalence is highest [11]. This is however not the case in this study probably because it is a single centre, hospital based study. The majority of the affected patients in this series had NHL which is consistent with various other reports $[2,12,15]$, and this further reinforced the AIDS-defining status of NHL. It is however interesting to note that there was no case of AIDS associated $\mathrm{BL}$ in spite of the high percentage of $\mathrm{BL}$ in this series and
Table 1. Table showing the percentage of HIV-positive patients amongst the different Lymphoma sub-group. (JAN.1993 - AUG 2008).

\begin{tabular}{ccc}
\hline Lymphoma type & Total & HIV reactive (\%) \\
\hline NHL & 109 & $6(5.5 \%)$ \\
HL & 28 & 0 \\
CLL & 76 & $3(3.9 \%)$ \\
BL & 178 & 0 \\
Total & 291 & $9(2.3 \%)$ \\
\hline NHL = Non Hodgkin's Lymphoma. HL = Hodgkin's \\
Lymphoma. CLL = Chronic Lymphocytic Leukaemia. BL $=$ \\
Burrkit's Lymphoma.
\end{tabular}

more importantly the endemicity of BL in this part of the world and also BL being commonest cancer in Nigerian children [17]. This result is however in tandem with an earlier report by Chitsike et al. [9] from Zimbabwe. The probable explanation may be because BL is predominantly a childhood malignancy and/or as a result of yet unidentified factors.

Also, none of the patients with HL had HIV infection and this is similar to what was earlier reported from Kenya [15]. The clinical presentation of these patients characterized by advanced clinical stage and high histological grade is similar to earlier report [11]. However, the median survival of 2 weeks is abysmally low compared to a median of 7-8 months previously reported [11]. However, this should be viewed against the background of relatively high cost of chemotherapeutic agents, poverty, budding health insurance and presentation in advanced clinical stage of the disease [18].

\section{Conclusion}

The prevalence of AIDS-related lymphomas is $2.3 \%$ in this series compared to $4.4 \%$ observed in the general population. However, it is interesting that no single case of AIDS-associated Burrkit's lymphoma was recorded despite its endemicity in this part of the world. All our patients presented at a very advanced stage of the disease with a significantly shortened survival.

\section{References}

1. Lerime AM. AIDS -related malignancies: The emerging epidemic J. Natt Cancer Inst. 1993;85:1382-1397.

2. Raphael M. Borisch B, Jaffe ES. Lymphomas associated with infection by HIV. In Tumours of Haematopoietic and lymphoid Tissues, WHO classifications of Tumours IARC press 2001:260263.

3. Mbulaiteve SM, Biggar RJ, Goedert JJ, Engels EA. Immune deficiency and risk and risk for malignancy among persons with AIDS. J Acquir Immune Defic Synd 2003 Apr 15;32(5):527533.

4. Gottlieb MS, Schroff R, Schanker HM, et al. Pneumocystic Carini pneumonia and mucosal candidiasis in previously healthy homosexual men: evidence of a new acquired cellular immunodeficiency N. Engl J Med. 1981; 305: 14251431.

5. Beral V, Peterman T, Berkelman R, Jaffe H. AIDS - associated non-Hodgkins lymphoma. Lancet 1991;337: 805-809. 
6. Goedert JJ. The epidemiology of acquired immunodeficiency syndrome malignancies. Semin Oncol. 2000; 27: 390-401.

7. Alexander DD, Mink PJ, Ademi H, et al. The Non-Hodgkin lymphomas: A review of epidemiologic literature. Int. J. Cancer. 2007; 120: 1-39

8. Engels EA, Biggar RJ, Hall HI, et al. Cancer risk in people infected with human immunodeficiency virus in the United States Int J. Cancer. 2008 Jul 1;123(1):187-194

9. Ocheni S, Aken'ova YA. Associated between HIV/AIDS and malignancies in a Nigerian tertiary institution. West Afr. J. Med. 2004 Apr- Jun; 23(2): 151 - 155.

10. Chitsike J, Siziya S. Sero-prevalence of human immunodeficiency virus type I (HIV-1) infusion in childhoods malignancy in Zimbabwe Cent. Afr. J. Med. 1998 Oct; 44 (10) 242- 245.

11. Otieno NW, Banura C, Mbidde - Katongole E, et al Therapeutic challenges of AIDS - related Non- Hodgkin's Lymphoma in the United States and East Africa. Journal of Nat. Cancer Inst. Vol 94(10); 2002: 718 - 726.
12. Bani BJ. The haematological features of HIV infection. Br. J. Haematol. 1997;99:1-8.

13. Akanmu AS AIDS-associated malignancies Afr. J. Med. Med. Sci. 2006 Dec; 35 Suppl: 57- 70.

14. 2005 National HIV/Syphilis sero-prevalence sentinel survey among pregnant women attending antenatal clinics. Federal Ministry of Health Department of Public Health, National AIDS/STDs Control Programme, Technical Report April 2006.

15. Lazzi S, Ferrari F, Nyongo A, et al HIV - associated malignant lymphomas in Kenya (Equatorial Africa). Hum. Pathol. 1999 Oct: 30(10): 1296 - 70.

16. Rukujei AD. Epidemiology of HIV/AIDS in Nigeria. Nig. J. Med. 1998; 7:8-10.

17. Durosinmi MA. Cancer: the burden, the control. Inaugural lecture series 213. Obafemi Awolowo University, Nigeria. Obafemi Awolowo University Press Ltd, 2007.

18. Durosinmi MA, Adediran I. Management of cancer under structural adjustment programme (SAP): Experience in Ile-Ife Nigeria. NMJ 1993; 25: 92-96. 